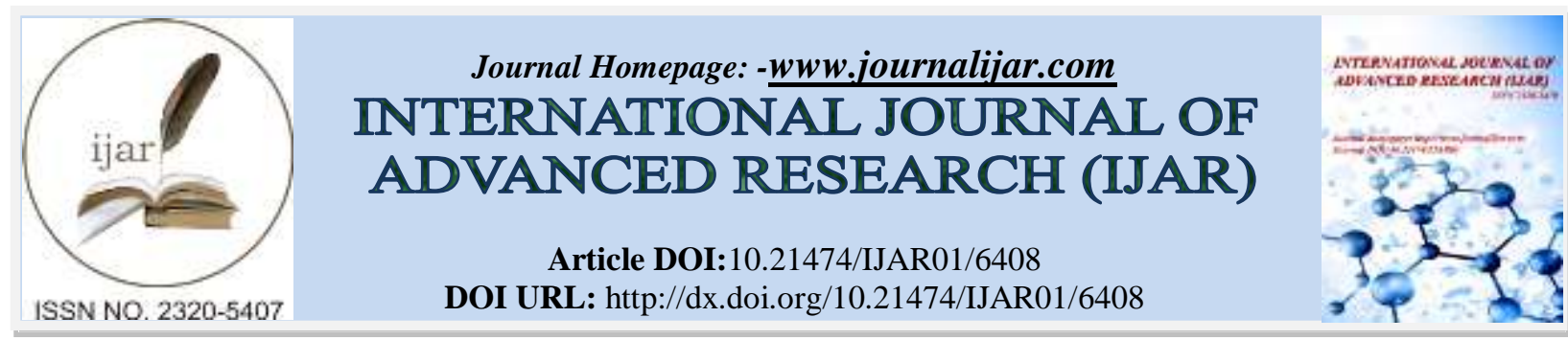

RESEARCH ARTICLE

\title{
AN OVERVIEW ON NON STEROIDAL ANTI-INFLAMMATORY DRUG AS A TRIGGER OF CARDIOVASCULAR DISEASE.
}

\author{
Jossy P Jose,Shanmuga Sundaram Rajagopal and Sambath kumar Ramanathan. \\ Department of Pharmacy Practice, J.K.K. Nattraja College of Pharmacy, Komarapalayam-638183, Tamil Nadu, \\ India (Affiliated to the Tamilnadu Dr. MGR Medical University, Chennai, India).
}

\section{Manuscript Info}

Manuscript History

Received: 01 December 2017

Final Accepted: 03 January 2018

Published: February 2018

Keywords:-

Non steroidal anti inflammatory drugs, cardio-vascular events, prostaglandins, Cyclooxygenase- 2 inhibitors.

\begin{abstract}
Nonsteroidal anti inflammatory drugs which are widely used by elderly patients. It have undesirable side effect including ulcers, bleeding, kidney failure and raised risk of heart and stroke. Mechanism of action, prolonged exposure to any class of non steroidal anti inflammatory drugs has been shown to have potential adverse effects on cardiovascular events in patients with or without pre existing cardiovascular conditions, depending on the duration and dosage of these drugs. Patient which having pre-existing coronary artery disease, hypertension, and history of stroke are at the higher risk of cardiovascular disease after taking non steroidal anti inflammatory drugs. The use of non steroidal anti inflammatory drugs with other antiplatelet drugs (except aspirin) increased the rate of cardiovascular events.Cyclooxygenase-2 inhibition results in a reduction of prostaglandin synthesis and is associated with both anti natriuretic and vasoconstrictor effects. Inhibition of cyclooxygenase- 2 may lead to reductions in both prostagladinE2 and prostacyclin. Inhibition of ProstaglandinE2 may promote an acute relative reduction in daily urinary sodium excretion. The kidneys in patients with normal kidney function will tend to increase sodium excretion to compensate for the antinatriuretic effects of the Cyclooxygenase-2 selective inhibitor or Non steroidal anti inflammatory drug to maintain homeostasis of sodium balance. This phenomenon occurs in lack of a elevation in blood pressure or sustained rise in plasma volume. Suppression of the Cyclooxygenase -2-dependent formation of prostaglandinI2 by the coxibs might influence in patients to myocardial infarction or thrombotic stroke. Thus, reduction in prostaglandinI 2 formation, lead to a expected elevation of blood pressure, accelerate atherogenesis, patients receiving coxibs to an exaggerated thrombotic response to the rupture of an atherosclerotic plaque.
\end{abstract}

Copy Right, IJAR, 2018,. All rights reserved.

\section{Introduction:-}

NSAID'S which are widely used by elderly patients. The beneficial and harmful effect of NSAID'S are related primarily to their holding back of PG synthesis ${ }^{1}$.Although prostaglandin have both vasodilator and vasoconstrictor

Corresponding Author:-Jossy P Jose.

Address:-Department of Pharmacy Practice, J.K.K. Nattraja College of Pharmacy, Komarapalayam58 638183, Tamil Nadu, India (Affiliated to the Tamilnadu Dr. MGR Medical University, Chennai, India). 
action. The net effect of NSAID are to elevate systemic vascular resistance thereby, lower renal perfusion in affected individuals $^{2}$.NSAIDS also have undesirable side effect including ulcers ,bleeding, kidney failure and raised risk of heart and stroke ${ }^{3,4}$ one of the mechanism which related to the adverse effect of NSAIDs is the generation of oxidative stress. Cyclooxyenase (COX)-2 selective inhibitors are developed to create a new class of NSAID'S with properties similar to those of non selective NSAIDS ${ }^{5}$ Recent evidence suggest that some doses of the COX-2 selective inhibitors and some traditional NSAID'S are associated with superior risk of adverse cardiovascular events.

\section{Types Of Nsaid:-}

NSAID can be classified according to their mechanism of action. Ibuprofen and naproxen involve in non selective NSAID, inhibit both cyclooxygenase-1(COX-1) and cyclooxygenase-2(COX-2) enzymes. Second class of NSAIDs (celecoxib and rofecoxib) called COX-2 selective inhibitors targets only the COX-2 pathway. During the administration of NSAIDs COX selectivity considered as a determining factor. Another class of semiselective NSAIDs (indomethacin, meloxicam, and diclofenac) have a higher affinity towards COX-2 but have a tendency to inhibit the COX-1 pathway also ${ }^{6}$. However, rather than mechanism of action, prolonged exposure to any class of NSAIDs has been shown to have potential adverse effects on cardiovascular events in patients with or without pre existing cardiovascular conditions, depending on the duration and dosage of these drugs. Patient which having preexisting coronary artery disease, hypertension, and history of stroke are at the higher risk of cardiovascular disease after taking NSAIDS ${ }^{7,8}$. The raised selectivity of COX-2 has reported high risk of CVD ${ }^{9,10}$.

\section{Mechanism Of Nsaids:-}

The COX-1 isoform is appeared in most tissues which regulates the synthesis of prostaglandins (PGs). COX-1 is the unique form of the enzyme immature platelets which also be seen in the vascular endothelium, the gastrointestinal epithelium, brain, spinal cord, and kidney. The COX-2 isoform plays an key role in induction of inflammation in response to injury, as well as later repair of inflammation. During angiogenesis, wound healing and in a variety of epithelial cells cancer, COX-2 may be induced by bacterial endotoxins, cytokines, growth factors which expressed in atherosclerotic plaques. ${ }^{10,11}$. NSAIDS drugs competitively inhibit the cyclo-oxygenase enzyme (subtypes COX-1 and COX-2), lead to inhibition of PGS and thromboxane (TX) synthesis in peripheral tissues and nerves. PGs regulate a number of physiological functions including gastric mucosal protection, vasodilatation and platelet adhesion.

\section{Cardiovascular Disease (Cvd) Induced By Nsaids:-}

According to CVD related outcomes in patients enrolled in the REACH (Reduction of Atherothrombosis for Continued Health) registry showed that in patients using NSAIDs having the risk of stable atherothrombosis, myocardial infarction and cerebrovascular conditions. Also the use of NSAIDs with other antiplatelet drugs (except aspirin) increased the rate of cardiovascular events like cardiovascular death, myocardial infarction, and stroke $^{5}$.Although a few studies suggest that COX selectivity does not seem to be a determining factor for myocardial infarction ${ }^{9,12}$. Several studies suggest that coxibs elevate the risk of CVD compared to non selective NSAIDs. ${ }^{13-}$

${ }^{14}$.The main risk of cardiovascular events associated with COX-2 inhibitors was an increased risk of myocardial infarction $^{15}$. Three coxibs — celecoxib, rofecoxib, and valdecoxib — have been approved for use by the FDA; a fourth, etoricoxib, has been approved by the European Regulatory authority and fifth lumiracoxib are currently under consideration for FDA approval. Rofecoxib has now been withdrawn from the market by Merck. This action was taken because of incidence of serious thromboembolic adverse events in the group receiving $25 \mathrm{mg}$ of rofecoxib per day as compared with the placebo group. Blood pressure was elevated in patients in the rofecoxib group early in the course of the study, but the incidence of myocardial infarction and thrombotic stroke in the two groups began to reduce after a year or more of treatment. Suppression of the COX-2-dependent formation of prostaglandinI2 by the coxibs might influenced in patients to myocardial infarction or thrombotic stroke. Thus, reduction in prostaglandinI2 formation, lead to a expected elevation of blood pressure, accelerate atherogenesis, patients receiving coxibs to an exaggerated thrombotic response to the rupture of an atherosclerotic plaque. In a clinical trial, celecoxib was differentiated with Ibuprofen or diclofenac ${ }^{16,17}$. In a report, celecoxib appeared as having a more encouraging gastrointestinal-side-effect profile, and no increase in cardiovascular risk was revealed. In a study which on the patients undergoing coronary-artery bypasses grafting,treatments with the valdecoxib prodrug, parecoxib was head to a cluster of cardiovascular events, and the drug was rejected by the FDA. More over, several semi selective NSAIDs like diclofenac and meloxicam and non selective NSAIDs including naproxen and ibuprofen have also been shown a hike in the incidences of CVD. Diclofenac enhance the occurrences of myocardial infarction and stroke even at lower doses of $<150 \mathrm{mg} /$ day compared to naproxen at doses of $>1000 \mathrm{mg} / \mathrm{day}{ }^{18}$. Naproxen reduces 
cardiovascular events than other commonly used NSAIDs, because it pretend the activity of acetylsalicylic acid (aspirin) by obstructing cyclooxygenase platelet thromboxane B2 ${ }^{19}$.Aspirin is the only known NSAID which has antithrombotic activity through the inhibition of platelet aggregation in the artery of the heart thereby exhibiting cardio protective effects.

\section{Cox Inhibitors In Patients With Hypertension:-}

Co administration of NSAIDs or COX-2 selective inhibitors with antihypertensive agents is $\mathrm{q}$ common ${ }^{20}$.The NSAID'S such as ibuprofen, indomethacin, and naproxen could increase mean arterial pressure by as much as 5 to 6 $\mathrm{mm} \mathrm{Hg}$ in hypertensive patients ${ }^{21-23}$. Sustained BP elevations in the elderly are associated with increases in the risk of both ischemic and hemorrhagic stroke, congestive heart failure, and ischemic cardiac events ${ }^{24-26}$. COX-2 inhibition results in a reduction of PG synthesis and is associated with both anti natriuretic and vasoconstrictor effects. Inhibition of COX-2 may lead to reductions in both PGE2 and prostacyclin. Inhibition of PGE2 may promote an acute relative reduction in daily urinary sodium excretion ${ }^{27-29}$. With in a few days, the kidneys in patients with normal kidney function will tend to increase sodium excretion to compensate for the antinatriuretic effects of the COX-2 selective inhibitor or NSAID to maintain homeostasis of sodium balance. This phenomenon occurs in lack of a elevation in BP or sustained rise in plasma volume ${ }^{30,31}$. The NSAIDs and COX-2 selective inhibitors may impair the vasodilatory benefits of prostacyclin due to water and sodium imbalance. Loss of this mechanism of vasodilatation in the face of numerous vasoconstrictors (eg, angiotensin 2, nor epinephrine, and endothelin) may potentially lead to increases in systemic vascular resistance and, subsequently, to increases in mean arterial pressure.

\section{Conclusion:-}

Mechanism of action, prolonged exposure to any class of NSAIDs has been shown to have potential adverse effects on cardiovascular events in patients with or without pre existing cardiovascular conditions, depending on the duration and dosage of these drugs. Patient which having pre-existing coronary artery disease, hypertension, and history of stroke are at the higher risk of cardiovascular disease after taking NSAIDS. The co-administration of NSAID'S and anti hypertensives shows mild elevation in blood pressure. The use of NSAIDs with other antiplatelet drugs (except aspirin) increased the rate of cardiovascular events like cardiovascular death, myocardial infarction, and stroke.

\section{Reference:-}

1. Brooks PM, Day RO. Non-steroidal anti-inflammatory drugs: differences and similarities.N Engl J Med. 1991; 324:1716-25.

2. Clive DM, Stoff JS. Renal syndromes associated with non steroidal anti-inflammatory drugs. N Engl J Med. 1984; 310:563-72.

3. Silverstein FE, Faich G, Goldstein JL. Gastrointestinal toxicity with celecoxib vs non steroidal antiinflammatory drugs for osteoarthritis and rheumatoid arthritis. The CLASS study: a randomized controlled trial. JAMA. 2000; 284:1247-55.

4. Bombardier C, Laine L, Reicin A, Shapiro D . Comparison of upper gastrointestinal toxicity of rofecoxib and naproxen in patients with rheumatoid arthritis. N Engl J Med 2000; 343:1520-1528

5. A.Helin-Salmivaara,A.Virtanen,R.Vesalainen,etal., NSAID use and the risk hospitalization for first myocardial infarction in the general population: a nationwide case-control study from Finland. Eur. Heart J.2006; 27:16571663.

6. Amer M, Bead VR, Bathon J, Blumenthal RS, Edwards DN. Use of nonsteroidal anti-inflammatory drugs in patients with cardiovascular disease: a cautionary tale. Cardiol Rev. 2010; 18:204-12

7. A.Rostom, P. Moayyedi, and R. Hunt. Canadian consensus guidelines on long-term nonsteroidal antiinflammatory drug therapy and the need for gastro protection: benefits versus risks. Alimentary Pharmacology\& Therapeutics. 2009; 29:481-496.

8. Farkouh ME and Greenberg BP, An evidence-based review of the cardiovascular risks of nonsteroidal antiinflammatory drugs. Am J Cardiol.2009;103:1227-3

9. Mukherjee D, Nissen SE, Topol EJ. Risk of cardiovascular events associated with selective COX-2 inhibitors. JAMA. 2001; 286:954-9.

10. 11 Kohli P, Steg PG, Cannon CP, smith SC Jr, Eagle KA, Ohman EM et al. NSAID use and association with cardiovascular outcomes in outpatients with stable atherothrombotic disease. AmJ Med.2014;127:53-60 
11. Mamdani M ,Juurlink DN, Lee DS, Rochon PA, Kopp A, Nagile G et al. Cyclooxygenase- 2 inhibitors versus non-selective non-steroidal anti-inflammatory drugs and congestive heart failure outcomes in elderly patients: a population-based cohort study.Lancet. 2004; 36:1751-6

12. Mukherjee D, Nissen SE, Topol EJ.Risk of cardiovascular events associated with selective COX-2 inhibitors. JAMA. 2001. 22-29; 286:954-9

13. Bhala N, Emberson J, Merhi A, Abrmson S, Arber N, Baron JA et al. Vascular and upper gastrointestinal effects of non-steroidal anti-inflammatory drugs: meta-analyses of individual participant data from randomised trials. Lancet. 2013; 382: 769-779

14. Kearney PM, Baigent C,Godwin J, Halls H, Emberson JR ,Patrono C. Do selective cyclo-oxygenase-2 inhibitors and traditional non-steroidal anti-inflammatory drugs increase the risk of atherothrombosis? Metaanalysis of randomised trials. BMJ. $2006 ; 332: 1302-8$

15. Garret A,FitzGerald M.D, Carlo Patrono M.D The coxibs, selective inhibitors ofcyclooxygenase-2.N Engl J Med 2001; 345:433-442

16. FitzGerald GA. COX-2 and beyond: approaches to prostaglandin inhibition in human disease. Nat Rev Drug Discov. 2003:2:879-90

17. Zhang E. Ding L, Song Y. Adverse effects of cyclooxygenase 2 inhibitors on renal and arrhythmia events: meta-analysis of randomized trials. JAMA2006; 29:1619-1632.

18. Capone ML, Sciulli MG, Tacconelli S, Grana M,Ricciotti E, Renda G etal. Pharmacodynamic interaction of naproxen with low-dose aspirin in healthy subjects. J Am Coll Cardiol. 2005; 45(8):1295-301

19. Undas A, Brummel-Ziedins KE, Mann KG. Antithrombotic properties of aspirin and resistance to aspirin: beyond strictly antiplatelet actions. Blood. 2007 ;109:2285-92.

20. White WB. Hypertension associated with therapies to treat arthritis and pain. Am Heart Assoc.2004; 44: 123124.

21. Janet E, Jennifer J, David T.A meta-analysis of the effects of nonsteroidal anti-inflammatory drugs on blood pressure. Arch Intern Med. 1993; 153:477- 484.

22. Johnson AG, Nguyen TV, Day RO. Do nonsteroidal anti-inflammatory drugs affect blood pressure? A metaanalysis. Ann Intern Med. 1994; 121: 289-300.

23. White WB. Benefits of antihypertensive therapy in older patients with hypertension. Arch Intern Med.2000; 160:149-150.

24. ALLHAT Officers and Coordinators for the ALLHAT Collaborative Research Group. Major cardiovascular events in hypertensive patients randomized to doxazosin vs chlorthalidone: the Antihypertensive and LipidLowering Treatment to Prevent Heart Attack Trial (ALLHAT).JAMA. 2000;283: 1967-1975.

25. Julius S, Kjeldsen SE, Weber M, Brunner HR, Ekman S, Hansson L et al. Outcomes in hypertensive patients at high $\mathrm{CV}$ risk treated with regimens based on valsartan or amlodipine: the VALUE randomised trial. Lancet.2004;19: 363:2022-2031.

26. Morgan TO, Anderson A, Bertram D. Effect of indomethacin on blood pressure in elderly people with essential hypertension well controlled on amlodipine or enalapril. Am JHypertens.2000; 13:1161-1167.

27. Schwartz JI, Vandormael K, Malice MP, Kalyani RN, Lasseter KC, Holmes GB et al .Comparison of rofecoxib, celecoxib, and naproxen on renal function in elderly subjects receiving a normal-salt diet. Clin Pharmacol Ther. 2002; 72:50-61.

28. Simon LS, Smolen JS, Abramson SB, Appel G, Bombardier C, Brater DC.Controversies in COX-2 selective inhibition. J Rheumatol. 2002; 29:1501-1510.

29. Brater DC. Effects of nonsteroidal anti-inflammatory drugs on renal function: focus on cyclooxygenase-2selective inhibition. Am J Med.1999; 107:65S-70S.

30. Whelton A, Schulman G, Wallemark C, Drower EJ, Isakson PC, Verburg KM, Geis GS. Effects of celecoxib and naproxen on renal function in the elderly. Arch Intern Med. 2000; 160:1465-1470. 